DOI: https://doi.org/10.46630/phm.12.2020.07

Jean-Jacques A. Tatin-Gourier ${ }^{1}$

Article de synthèse

Université de Tours

УДК 811.133.1'373.43:821.133.1

ICD - Interactions culturelles et discursives

Reçu : le 17/2/2020

\title{
UNE RÉFLEXION INÉDITE SUR LE FRANÇAIS, LANGUE EN DEVENIR : LA NÉOLOGIE (1801) DE LOUIS SÉBASTIEN MERCIER
}

Après avoir rappelé l'acceptabilité croissante du néologisme au cours du XVIIIle siècle, cette communication rappelle l'essor des néologismes politiques au cours de la Révolution. Le Nouveau Paris, suite que Louis Sébastien Mercier donne en 1799 au Tableau de Paris, dénonce toutefois la violence induite, durant la Terreur, par les « abus de mots ». Mais dans son ouvrage intitulé Néologie (1801), Louis Sébastien Mercier proclame le caractère hautement positif du néologisme pour une littérature appelée à s'engager dans des voies nouvelles.

Mots clés : Mercier, Paris, néologismes, Révolution, abus des mots, littérature

Notre objectif n'est pas ici de débattre de l'ensemble des problèmes que posent aujourd'hui les nouvelles manières de parler, les inventions ou les applications nouvelles des termes. Nous n'entrerons pas non plus dans la grande distinction de la néologie de forme ou lexicale (introduction d'un nouveau mot dans la langue soit par emprunt à une autre langue, soit par fabrication d'une nouvelle unité lexicale) et de la néologie de sens ou néologie sémantique, instauration d'un nouveau rapport du signifiant au signifié (généralement par le recours à la métaphore). Il importe aussi de prendre en compte le fait qu'en France, le principe de l'enrichissement de la langue française revêt un caractère officiel et est de nos jours pleinement accepté, avec toutefois la notion de contrôle toujours implicite. En effet le décret $n^{\circ} 96.602$ du 3 juillet 1996 relativement à l'enrichissement de la langue française a créé une commission de terminologie et néologie. Mais, on le sait, l'acceptabilité, le rôle et le statut du néologisme ont considérablement varié d'époque à époque (PREVOST, SABLAYROLLES 2012 : ch. III).

Cantonné au style burlesque au XVII ${ }^{e}$ siècle et majoritairement condamné au nom de la pureté langagière dont on pense communément qu'elle

\footnotetext{
${ }^{1}$ tatingourier@aol.com
} 
est désormais fixée et doit être maintenue comme telle 2 , le néologisme est tout au plus toléré chez les gens de «bon ton » et considéré comme " barbare » (BAR 1973: 43, 58) chez une populace qui doit être tenue à l'écart de toute innovation linguistique.

Des réactions dans le sens de l'acceptation du néologisme se dessinent toutefois dès le début du XVIII ${ }^{\mathrm{e}}$ siècle - et l'on trouve là les noms de Fontenelle, La Motte et Marivaux (ARMOGATHE 1973: 17, 28). Mais ces ouvertures suscitent en retour une hostilité aux " modernes » considérés comme de dangereux néologistes. Cette hostilité s'exprime particulièrement dans le Dictionnaire néologique de Pantalon Phœbus de Jean-Jacques Bel et Pierre Guyot Desfontaines qui connaît trois éditions de 1726 à 1728. Dans son Discours sur l'éloquence (1735), l'abbé d'Olivet est tout aussi catégorique dans sa dénonciation du néologisme. Mais en 1742 l'académicien Moncrif, qui prend le relais de Bayle, proclame dans un discours à l'Académie le caractère indispensable de l'acceptation des « mots qui manquent à la langue ». Et de plus en plus nombreux sont les écrivains qui, de Duclos à d'Alembert et à Marmontel (qui défend la nécessité d'une langue « cosmopolite » et par là créative de mots nouveaux) qui promeuvent la conception d'une langue transparente au progrès des idées, des arts, des connaissances et des échanges.

L'Académie est contrainte de suivre cette dynamique en distinguant la « néologie » considérée comme acceptable et le « néologisme » qui doit être dénoncé comme un abus. C'est au nom de l'utilité - notamment technique et scientifique mais aussi économique - que les Modernes confortés par le succès de l'Encyclopédie se déclarent partisans d'un néologisme qu'ils mettent en œuvre de plus en plus.

Dès les débuts de la Révolution française se développe un véritable enthousiasme pour le néologisme - néologisme d'ordre politique et institutionnel - : la Société des amateurs de la langue française créée en 1791 et chargée en quelque sorte de se substituer à l'Académie se donne pour but de « présenter la liste de tous les mots que nous devons à la Révolution »(DOMERGUE 1791 : 162). Durant les années révolutionnaires, la question du néologisme est évidemment indissociable d'une réflexion plus globale et sans précédent sur la langue politique et sa performativité. À la fin 1790, le Mercure national crée une tribune intitulée « Sur l'influence des mots et le pouvoir de l'usage » (KERALIO et al. 1790). La langue doit être " purifiée au feu de la liberté » selon les uns - les partisans de la révolution en cours. Les « abus de mots » doivent cesser selon les autres - les « modérés » qui, pour la plupart d'entre eux rejoignent les rangs de la contre-révolution. Les « disputes de mots » se multiplient donc.

\footnotetext{
${ }^{2}$ Vaugelas écrit dans ses Remarques : «Quand une langue a nombre et cadence en ses périodes, comme la Française l'a maintenant, elle est en sa perfection, et étant venue à ce point, on en peut donner des règles certaines qui dureront toujours » (VAUGELAS $1880: 23$ ).
} 
En 1791 le « grammairien patriote » François Urbain Domergue instaure deux espaces où les questions de la légitimité et de l'efficacité de la langue politique seront débattues : le Journal de la langue française et la Société délibérative de la langue française. C'est dans ce contexte qu'avec la chute de la monarchie, l'invasion des frontières et la proclamation de la république (août-septembre 1792) va se construire un champ lexical nouveau autour de la notion centrale de « salut public ». Avec l'élimination des Girondins (mai 1793), la dictature jacobine et l'accentuation de la Terreur, ce lexique nouveau plus que jamais martelé sera aussi la cible d'une critique de plus en plus systématique. Cette critique transparaît notamment dans les poèmes de prison d'André Chénier, dans les Mémoires de Madame Roland (l'égérie de la Gironde qui rédige ses mémoires dans les prisons de la Terreur). Mais elle ne sera vraiment systématisée qu'après la chute de Robespierre notamment avec l'essai de La Harpe, Du fanatisme dans la langue révolutionnaire (1797).

Louis Sébastien Mercier, l'auteur à succès, peu avant la Révolution, du Tableau de Paris, proche des Girondins et emprisonné comme tel sous la Terreur, publie après Thermidor deux œuvres - le Nouveau Paris, la Néologie - où peuvent entre autres se lire une réflexion sur le rôle de la langue dans l'établissement de la Terreur et peut-être plus encore une réflexion sur les potentialités de dépassement de cette langue qui s'est révélée fauteuse de terreur. Le néologisme se trouve au cœur de cette double réflexion.

Le Nouveau Paris n'est pas une simple suite du Tableau de Paris. Il s'agit avant tout pour Mercier de montrer comment les divers espaces parisiens parcourus ont avec les événements révolutionnaires - séquences terroristes comprises - acquis une charge mémorielle nouvelle. Les déferlements deviolence, à la fois dans les discours et dans les comportements - sont désormais indissociables des lieux citadins où ils se sont développés : « J'ai entendu s'écrier dans une section et je l'atteste : Oui, je prendrais ma tête par les cheveux, je la couperais, et l'offrirais au despote, je lui dirais : «Tyran, voici l'action d'un homme libre ! \ Ce sublime de l'extravagance était composé pour les classes populaires, il a été entendu, il a réussi. » (MERCIER 1994 : 19-20)

Il s'agit bien là, selon Mercier, d'une créativité langagière monstrueuse, mais d'une créativité tout de même impliquant d'ailleurs une forte théâtralisation. Dans son récit du procès de Louis XVI, Mercier évoque le député Legendre, boucher de son état et analphabète, proposant de découper le corps du roi en quatre-vingttrois morceaux destinés aux quatre-vingt-trois départements : « (...) il avait cru que la brutalité entrait dans la composition d'un républicain; et celui-là n'était pas républicain, qui ne mugissait pas comme un taureau et qui ne faisait pas des gestes comme pour assommer un bœuf. » (MERCIER 1994 : 186). Et Mercier de rapprocher cette langue nouvelle de l'argot des compagnons de Cartouche, le grand bandit populaire du midi du XVIII' siècle. 
Il importe dès lors pour Mercier d'analyser ce que fut cette monstrueuse expérience langagière d'une terreur en germe dès les premiers développements de la Révolution. Mais il importe tout autant pour lui de dépasser positivement, de manière créative et proprement littéraire cette expérience langagière de la Terreur. Dans le Nouveau Paris, Mercier proclame un impératif indissociablement historique, politique et littéraire : « faire son idiome » pour « peindre ce qui ne s'est jamais vu ». (MERCIER 1994 : 1819). Et Mercier n'hésite pas à introduire comme éléments historico-littéraires de comparaison Tacite et Shakespeare. Mercier écrivain, rescapé de la Terreur, se propose d'élaborer une langue littéraire qui soit à la hauteur des terribles événements révolutionnaires qu'il a traversés : «Ce sublime de l'extravagance étant composé pour les classes populaires, il a été entendu, il a réussi, et nous, nous ne ferions pas une langue, pour transmettre à nos derniers neveux ces incroyables phénomènes moraux et politiques, qui ont frappé d'une longue surprise et nos regards et notre entendement ? » (MERCIER 1994 : 20)

En 1801 la publication de la Néologie répond tout d'abord à cet objectif formulé dans le Nouveau Paris. Cependant dans cet ouvrage, Mercier se situe à un tout autre niveau plus spécifiquement littéraire et esthétique. Mercier y proclame hautement « l'indépendance absolue de (ses) idées » et se démarque avec force des étouffeurs de l'Institut auxquels il reproche un conservatisme linguistique foncier (vouloir « fixer la langue »). Mercier explicite en fait un présupposé essentiel de sa conception de la langue : langue et avant tout parole en perpétuel mouvement, ouverte aux emprunts des langues étrangères, des patois provinciaux et du français du Moyen-Âge et de la Renaissance, langue ouverte de plus à des créations lexicales toujours renouvelées avec un monde en devenir. C'est dans la Préface même de sa Néologie que Mercier expose cette conception avec toutes ses implications en matière de canon, de critique littéraire et de choix philosophiques : refus catégorique de l'esthétique classique et de ses règles, retour élogieux sur Rabelais, défense de Chateaubriand, rejet de Spinoza, des développements philosophiques sensualistes et matérialistes. Au-delà des développements critiques, interviennent aussi la réhabilitation de Descartes et des références positives à l'œuvre de Kant.

En un sens, dans la Néologie, et si on compare cet ouvrage au Nouveau Paris, la référence à l'expérience révolutionnaire peut apparaître très secondaire tant le texte de cet essai semble avant tout orienté vers l'avenir et constituer même un véritable manifeste. La référence à la Révolution est même explicitement minimisée : «J'ai écarté (à quelques exceptions près) les mots qui tiennent à la révolution, ainsi que les mots techniques des sciences et des arts; ils ont leur vocabulaire à part. » (MERCIER 1994 : 40)

Cette mise à distance de la Révolution et même de la philosophie des Lumières peut sembler paradoxale eu égard à la logique d'ensemble de 
l'œuvre de Louis Sébastien Mercier. La démarcation à l'égard de la langue de la Révolution est cependant très nette :

« La plupart de ces expressions sont fortes et vigoureuses, elles correspondaient à des idées terribles ; la plupart sont bizarres, elles appartenaient à la tourmente des événements ; et lorsque les vents sifflent, que le vaisseau est battu par une horrible tempête, qu'il touche à des écueils, l'on ne parle pas comme quand le zéphyr règne ; les matelots jurent, mais ils font la manœuvre qui sauve. Le temps n'est pas encore venu de bien peindre la lutte du crime et de la vertu, qui eut lieu dans l'enceinte de cette funeste Convention nationale, lutte énergique et longue. L'idiome fut tout aussi neuf que la position de la France. Les victimes et les bourreaux, tout fut empreint d'un grand caractère ; le courage fut égal. (...) Dans cette grande assemblée, le patriotisme y fut rage ; les bourreaux n'ont pas méprisé leurs victimes, et toutes les victimes tombèrent avec une dignité tranquille, comme se donnant elles-mêmes en sacrifice à leurs propres vertus. » (MERCIER 1994: 40)

Pour Mercier, l'essentiel semble se situer désormais au-delà de la mémoire de la Révolution pourtant toute proche : seul doit désormais compter l'avenir de la langue et des lettres et il est pour le moins inutile de revenir sur les traumatismes du passé fussent-ils récents et encore douloureux. Pourtant au fil de la lecture des notices de la Néologie, l'expérience de la Terreur semble bien encore présente dans les marges d'un texte qui se veut d'abord tendu vers l'avenir des lettres françaises. Les deux notices des néologismes abriter et afférocée sont significatives :

« Abriter. Voici l'orage, abritons-nous. Heureux qui, pendant les tempêtes révolutionnaires, a pu s'abriter sous un toit inconnu. »

" Afférocée. Et toutes ces têtes innocentes tombaient au bruit des applaudissements d'une multitude afférocée. » (MERCIER 2009 : 23)

En fin de compte pour Mercier, et malgré les pétitions de principe de la Néologie, la Révolution et ses violentes et douloureuses implications demeurent bien incontournable. Et c'est cette expérience même de la Révolution qui permet à Louis Sébastien Mercier d'affirmer le caractère positif et essentiel du néologisme pour l'essor de la littérature de l'avenir.

\section{Bibliographie}

\section{Sources}

BEL, GUYOT-DESFRONTAINES 1731 : BEL, Jean-Jacques et Pierre GUYOT-DESFONTAINES. Dictionnaire néologique à l'usage des beaux esprits $d u$ siècle, avec l'éloge historique de Pantalon-Phoebus. Paris : éditeur Michel-Charles Le Cène, 1731. 
MERCIER 1994 : MERCIER, Louis Sébastien. Le Nouveau Paris. Paris : édition établie sous la direction de Jean-Claude Bonnet, Mercure de France, 1994.

MERCIER 2009 : MERCIER, Louis Sébastien. Néologie ou vocabulaire des mots nouveaux, à renouveler ou pris dans des acceptions nouvelles. Établi, annoté et présenté par Jean Claude Bonnet. Paris : Belin, 2009.

VAUGELAS 1880 : VAUGELAS, Claude Favre de. Remarques sur la langue française, utiles à ceux qui veulent bien parler et bien écrire. Paris : Chassang éditeur, 1880.

DOMERGUE 1791 : DOMERGUE, François-Urbain. Journal de la langue française, Paris (1790) : 162-163.

KERALIO et al. 1790 : Keralio ERALIO M ${ }^{\text {lle }}$ de, MM. CARRA et Hugou de BASSVILLE. " Mercure national, ou Journal d'État et du citoyen (1790). Paris, $n^{\circ} 1-8$ (31 décembre 1789 - 30 août 1790).

\section{Ouvrages critiques}

ARMOGATHE 1973 : ARMOGATHE, Jean-Robert. « Néologie et idéologie dans la langue française du XVIII ${ }^{\mathrm{e}}$ siècle », Revue Dix-huitième siècle, $\mathrm{n}^{\circ} 5$ (1973) : 17-28.

BAR 1973 : BAR, Francis. « Les néologismes chez les burlesques du XVIII siècle ». Cahiers de l'AIEF (1973) : 45-58.

PREVOST, SABLAYROLLES 2012 : PREVOST, Jean et Jean-François SABLAYROLLES. Néologismes. Paris : H. Champion, 2012.

Жан-Жак А. Татен-Гурије

\section{НЕОБЈАВЉЕНО РАЗМИШЉАЬЕ О ФРАНЦУСКОМ, ЈЕЗИКУ У НАСТАЈАЮУ: НЕОЛОГИЈА (1801) ЛУЈА СЕБАСТИЈАНА МЕРСИЈЕА}

Након подсећања на све израженију прихватљивост неологизама током XVIII века, у раду се осврћемо на узлет политичких неологизама током револуције. У Новом Паризу, наставку књиге Слике Париза из 1799. године, Луј Себастијан Мерсије разоткрива насиље које се уводи током Терора путем ,злоупотребе речи”. Међутим, у делу насловљеном Неологија (1801), Луј Себастијан Мерсије обнародује изузетно позитиван карактер неологизама у књижевности која се отвара ка новим путевима креације.

Кључне речи: Мерсије, Париз, неологизми, Револуција, злоупотреба речи, књижевност 